\title{
First impressions from the PRISMA hyperspectral mission
}

\author{
Prateek Tripathi* and Rahul Dev Garg \\ Geomatics Engineering, Department of Civil Engineering, Indian Institute of Technology, Roorkee 247 667, India
}

\begin{abstract}
PRISMA is a hyperspectral mission launched by the Italian Space Agency on 21 March 2019. PRISMA is the spaceborne hyperspectral sensor which provides imageries of the Earth's surface with (i) global coverage of $30 \mathrm{~km} \times 30 \mathrm{~km}$ with a total acquisition capacity of $1800 \mathrm{~km}$ in a continuous strip, and (ii) spectral resolution of $12 \mathrm{~nm}$ for the contiguous bands $(400$ $2500 \mathrm{~nm}$ wavelength). This study presents a review of the hyperspectral datasets from PRISMA for geological applications. A few geological regions from India are selected to check the capability of the PRISMA datasets. Dimensionality reduction and spectral analysis were performed and narrowband indices were generated. Few constraints with the previous hyperspectral sensors, i.e. large swath with a medium resolution camera on-board, are now covered in the PRISMA mission. This study is focused on the characteristics and compatibilities of the PRISMA hyperspectral sensor and will be beneficial to the scientific and users community.
\end{abstract}

Keywords: Geological applications, hyperspectral remote sensing, imaging spectroscopy, mineral exploration, spectral analysis.

HYPERSPECTRAL remote sensing, also known as imaging Spectroscopy, acquires imageries in the wavelength range $380-2500 \mathrm{~nm}$. This technique offers a dynamic and unique method to identify and characterize minerals in the visible and near-infrared (VNIR) and shortwave infrared (SWIR) wavelength ranges. It collects data in narrow and contiguous bands that can be utilized in many fields like forest analysis, precision agriculture, inland and coastal waters, climate change and environmental research, raw materials exploration, mining-soil degradation and soil properties $^{1}$. In the last few decades, several countries have used airborne and spaceborne hyperspectral sensors. There are a few hyperspectral missions, including NASA's, Hyperion under earth observing ${ }^{2}$ (EO)-1, Compact HighResolution Imaging Spectrometer (CHRIS) on-board the Proba-1 (European Space Agency, ESA), which work with various view angles to measure spectral reflectance ${ }^{3}$. In 2018, the Indian Space Research Organization (ISRO) launched the hyperspectral imaging satellite (HySIS) ${ }^{4}$.

\footnotetext{
*For correspondence. (e-mail: tprateek59@gmail.com)
}

These hyperspectral missions were launched to demonstrate the capabilities of high spectral resolution-based remote sensing techniques for the development of various algorithms and related applications. These hyperspectral missions encouraged the research community to develop various algorithms and methods in the domain of mineral exploration. However, unfortunately, none of these satellites provides the latest global processed datasets to the research community.

The Italian Space Agency launched the hyperspectral satellite ${ }^{5}$, PRISMA (PRecursore IperSpettrale dellaMissione Applicativa) on 21 March 2019 (French Guiana). PRISMA operates in two modes, one for downloading of the data, and another for acquisition and downlinking ${ }^{6}$. The main aim of this mission is to provide remote sensing datasets to the scientific and student community for earth observation and risk management ${ }^{7}$. On 21 May 2020, the Italian Space Agency made the PRISMA datasets free to download for its users ${ }^{8}$. It is a massive relief to the hyperspectral community as this mission is still in acquisition mode; hence, allowing users to request new datasets. This study presents an overview of the PRISMA hyperspectral mission, a few datasets and their capability in geological applications.

\section{PRISMA mission: architecture, specifications and modes of acquisition}

PRISMA instrument works on the concept of the pushbroom imaging scanning ${ }^{9}$. With an operational lifetime of five years, the satellite is mainly composed of the electrooptical payload, and the payload data handling and transmission subsystem (PDHT). The PRISMA payload has an imaging spectrometer (or hyperspectral imager) to capture images in a series of contiguous spectral bands covering the wavelength range from 400 to $2500 \mathrm{~nm}$, and a panchromatic camera with a resolution of $5 \mathrm{~m}$ that can be fused with other multispectral sensors available for improved visual image interpretation and information retrieval $^{1,10}$ (Table 1). The PRISMA system has a daily imaging capability ${ }^{1,6}$ of $\sim 200,000$ sq. $\mathrm{km}$, and can deliver the hyperspectral imagery for the area of interest (Figure $1)$. The primary area of interest covers the $180^{\circ} \mathrm{W}-180^{\circ} \mathrm{E}$ long and $70^{\circ} \mathrm{S}$ to $70^{\circ} \mathrm{N}$ lat. PRISMA delivers four types of standard products (Table 2). 


\section{REVIEW ARTICLES}

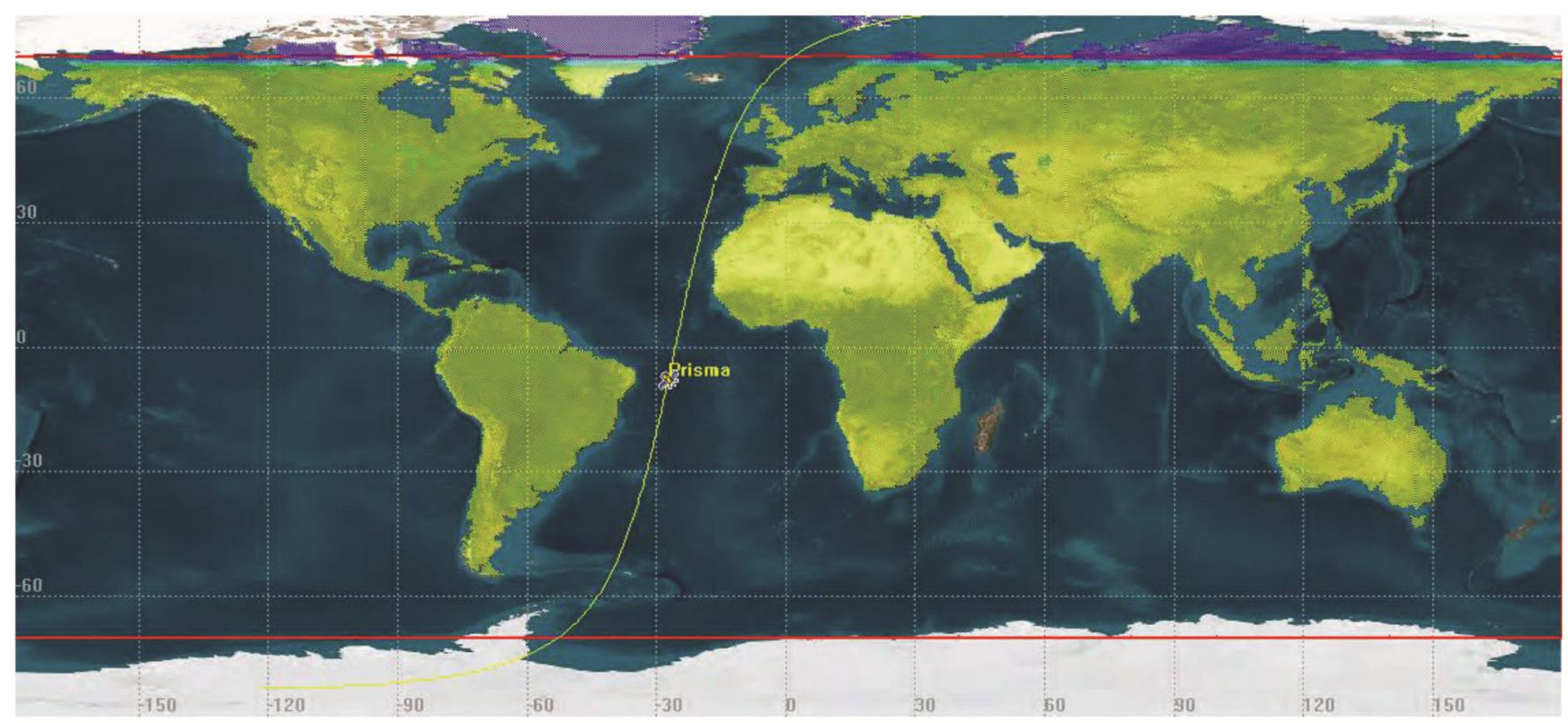

Figure 1. Global coverage of PRISMA hyperspectral satellite.

Table 1. Orbital parameters and satellite specifications for PRISMA hyperspectral satellite ${ }^{5,7}$

\begin{tabular}{ll}
\hline Orbit altitude reference & $615 \mathrm{~km}$ \\
Orbit altitude inclination & $97.851^{\circ}$ \\
Orbital period & $\sim 97 \mathrm{~min}$ \\
Nadir revisit time & 29 days \\
Relook time & 7 days \\
Swath/field of view & $30 \mathrm{~km} / 2.77^{\circ}$ \\
Ground sampling distance & Hyperspectral: $30 \mathrm{~m}$, PAN: $5 \mathrm{~m}$ \\
Spectral range & VNIR: $400-1010 \mathrm{~nm}(66$ bands $)$ \\
& SWIR: $920-2500 \mathrm{~nm}(173$ bands) \\
& PAN: $400-700 \mathrm{~nm}$ \\
Spectral width & $\leq 12 \mathrm{~nm}$ \\
Radiometric quantization & 12 bit \\
Signal-to-noise (SNR) ratio & VNIR SNR $>200: 1$ \\
& SWIR SNR $>100: 1$ \\
& PAN SNR $>240: 1$ \\
\hline
\end{tabular}

The end-users have four categories, including Italian Space Agency (ASI) people, international, national and generic users. PRISMA will give worldwide coverage with daily processing of 200 hyperspectral scenes up to level 2D product. As of now, there are about 40,000 products available in the archives $^{5,8,10}$.

Compared with hyperion $(7.5 \mathrm{~km})$, PRISMA has a broader swath $(30 \mathrm{~km})$. Also, the temporal frequency of PRISMA is 7-14 days, far better than Hyperion (14-30 days). The revisit frequency will felicitate efficient timeseries analysis using PRISMA hyperspectral data. Table 3 gives a comparison of the current hyperspectral sensors. PRISMA has the best signal-to-noise (SNR) ratio compared to other spaceborne hyperspectral sensors.

\section{Processing methods}

The datasets were downloaded from the PRISMA mission website (http://www.prisma-i.it/) through a simple registration process. Ground control points (GCPs) are available in the metadata provided by the PRISMA mission team for the processing of L2B, L2C and L2D datasets. The data download limit is one tile per day per average user $^{8}$. The downloaded data are in .he5 format, an HDFEOS5 data (hierarchical data format-earth observing system), an extension of HDF5. L2D datasets are georeferenced and stacked in Harris ENVI. The band indexing of the datasets is in decreasing order for both VNIR and SWIR bands ${ }^{5}$. The principal component analysis (PCA) was applied to check hydroxyl, iron oxide and other minerals as done by the previous researchers ${ }^{11}$. PCA reduces the number of image band inputs so that certain minerals will not be mapped, and increases the probability that others will be unequivocally mapped into only one of the principal component images. It is a popular technique used for alteration mapping ${ }^{11,12}$. A few spectral analysis techniques including derivative spectroscopy, narrow-band indices, spectral comparison, smoothing with derivative and unsupervised classification are also used in this work.

\section{Geological setting of the study area}

This study utilizes the PRISMA datasets for two Indian states, Rajasthan and Tamil Nadu (TN) (Figure $2 a$ ), as these two areas have geological significance, especially in terms of minerals. Banswara region of Rajasthan (Figure $2 b$ ) stretching between $23^{\circ} 03^{\prime}-23^{\circ} 56^{\prime} \mathrm{N}$ lat and 
Table 2. Data product formats provided for PRISMA by the Italian Space Agency (ASI) ${ }^{10}$

\begin{tabular}{lcr}
\hline Data level & \multicolumn{1}{c}{ Availability } & Description \\
\hline L1 & Hyperspectral and PAN & $\begin{array}{r}\text { Radiometrically corrected and calibrated radiance data in } \\
\text { physical units. This product includes: top-of-atmosphere } \\
\text { spectral radiance, cloud mask, sun-glint mask; calibration and } \\
\text { characterization data used and classification mask. }\end{array}$ \\
L2B & Hyperspectral and PAN & $\begin{array}{l}\text { Geolocated at ground spectral radiance product. } \\
\text { L2C }\end{array}$ \\
Hyperspectral and PAN & $\begin{array}{r}\text { Geolocated at-surface reflectance product. This includes aerosol } \\
\text { characterization product (VNIR), water vapour map product } \\
\text { (HYP) and cloud characterization. }\end{array}$ \\
L2D & Hyperspectral and PAN & Geocoded version of the level 2c products. \\
\hline
\end{tabular}

Table 3. Comparison of different hyperspectral sensors $s^{4,7,57-60}$

\begin{tabular}{|c|c|c|c|c|c|c|}
\hline Instrument & PRISMA & Hyperion & CHRIS PROBA & $\begin{array}{l}\text { AVIRIS } \\
\text { (airborne) }\end{array}$ & HySIS & HySI \\
\hline Agency/year & $\begin{array}{l}\text { Italian Space Agency (ASI), } \\
\quad 2019\end{array}$ & NASA (2000-17) & ESA (2001) & NASA (1986) & ISRO (2018) & ISRO (2008) \\
\hline Spectral range $(\mu \mathrm{m})$ & $\begin{array}{l}\text { PAN }=0.4-0.7 \text { VNIR } \\
(66 \text { bands })=0.4-1.01 \\
\text { SWIR }(173 \text { bands })=0.92-2.5\end{array}$ & $\begin{array}{l}\text { VNIR }(70 \text { bands })= \\
0.35-1.05 \\
\text { SWIR }(173 \text { bands })= \\
\quad 0.85-2.57\end{array}$ & $\begin{array}{l}\text { Visible }=0.4-0.7 \\
\text { NIR }=0.7-1.05\end{array}$ & $0.38-2.5$ & $\begin{array}{l}\text { VNIR }=0.4-0.95 \\
\text { SWIR }=0.85-2.4\end{array}$ & $\begin{array}{l}\mathrm{VNIR}= \\
0.4-0.95\end{array}$ \\
\hline Swath (km) & 30 & 7.5 & $14-18$ & $1.9-11$ & 30 & 129.5 \\
\hline $\begin{array}{l}\text { Spatial resolution } \\
\quad(\mathrm{m})\end{array}$ & $\begin{array}{l}\mathrm{PAN}=5 \\
\mathrm{VNIR}-\mathrm{SWIR}=30\end{array}$ & 30 & $\begin{array}{l}18(19 \text { bands }) \\
\text { or } 36 \\
\text { ( } 63 \text { bands })\end{array}$ & $\begin{array}{l}\text { 4-20 } \\
\text { (481 bands) }\end{array}$ & $\begin{array}{l}30 \\
\text { (316 bands) }\end{array}$ & $\begin{array}{l}505.6 \\
\text { ( } 64 \text { bands })\end{array}$ \\
\hline $\begin{array}{l}\text { Spectral resolution } \\
\quad(\mathrm{nm})\end{array}$ & $\leq 12$ & 10 & $\begin{array}{l}10 @ 0.4 \mu \mathrm{m} \\
120 @ 1.05 \mu \mathrm{m}\end{array}$ & $5 \pm 0.5$ & 10 & $<15$ \\
\hline Revisit (days) & $7(29)$ & 16 & 7 & - & NA & 24 \\
\hline SNR & $\begin{array}{l}\text { VNIR SNR }>200: 1 \\
\text { SWIR SNR }>100: 1 \\
\text { PAN SNR }>240: 1\end{array}$ & $\begin{array}{l}161(0.5 \mu \mathrm{m}) ; \\
147(0.7 \mu \mathrm{m}) ; \\
110(1.12 \mu \mathrm{m}) ; \\
40(2.12 \mu \mathrm{m})\end{array}$ & $\begin{array}{l}200 @ \text { a target } \\
\text { albedo of } 0.2\end{array}$ & $\begin{array}{l}>2000 @ \\
600 \mathrm{~nm}> \\
1000 @ \\
2200 \mathrm{~nm}\end{array}$ & NA & NA \\
\hline
\end{tabular}

$73^{\circ} 57^{\prime}-74^{\circ} 47^{\prime} \mathrm{E}$ long, has a variety of lithological units such as meta-sediments consisting of quartzite, mica schist, conglomerates, quartz-chlorite schist, phyllites, gneisses and intrusive as granites, pegmatite and amphibolite. The other areas are occupied by basalts of the Deccan trap ${ }^{13}$. The minerals found in Banswara are coarse, gritty schist, mica schist, phyllite, conglomerate (oligomictic and polymictic type), crystalline limestone, dolomite, intrusives (quartz vein, granite and pegmatite dykes), ultrabasic rock (thin bands of calc-tremolite schist), Deccan traps, granite gneiss and alluvium ${ }^{14-18}$ (Figure 3). Study area 1 also includes few parts of the Ratlam district of Madhya Pradesh.

The second study area is in Tirupattur district, TN, covering Ambur and Vaniyambadi towns and stretching between $12^{\circ} 11^{\prime}-12^{\circ} 47^{\prime} \mathrm{N}$ lat and $78^{\circ} 25^{\prime}-78^{\circ} 49^{\prime} \mathrm{E}$ long (Figure $2 c$ ). The third study area covers Gobichettipalayam and Kavindapadi of Erode district, TN, between $11^{\circ} 19^{\prime}-11^{\circ} 34^{\prime} \mathrm{N}$ lat and $77^{\circ} 21^{\prime}-77^{\circ} 40^{\prime} \mathrm{E}$ long (Figure $2 d$ ). The most widespread rocks are charnockites and associated gneiss ${ }^{19}$. These are pyroxene-bearing granulites and gneiss (Figure $4 a$ ). Study area 3 near Erode mainly consists of limestone, magnesite, dunite and bauxite (Figure $4 b$ ). The other rocks are migmatite, granite, iron ore, corundum and magnesite. The alkaline carbonatite complex is also found in study areas 2 and 3, intruded in migmatite gneiss, hornblende biotite gneiss and amphibolite. Carbonatite, which has mafic minerals like pyroxene, biotite, pyrochlore, apatite, sphene and zircon and industrial minerals, is also found in this area ${ }^{20-23}$. The lithological maps for study areas 1-3 shown in Figures 3 and 4 were prepared after downloading the required geodata from Bhukosh, the spatial data portal of the Geological Survey of India (GSI). The false-colour composite (FCC) was generated by band combination of 20,34 and 51 as RGB channels.

\section{Data dimensionality reduction}

PCA was used to check the multidimensionality of the datasets and generation of narrowband indices. PCA, based on decreasingly dominant variance or variability, helps in distinguishing the different mineralogical 

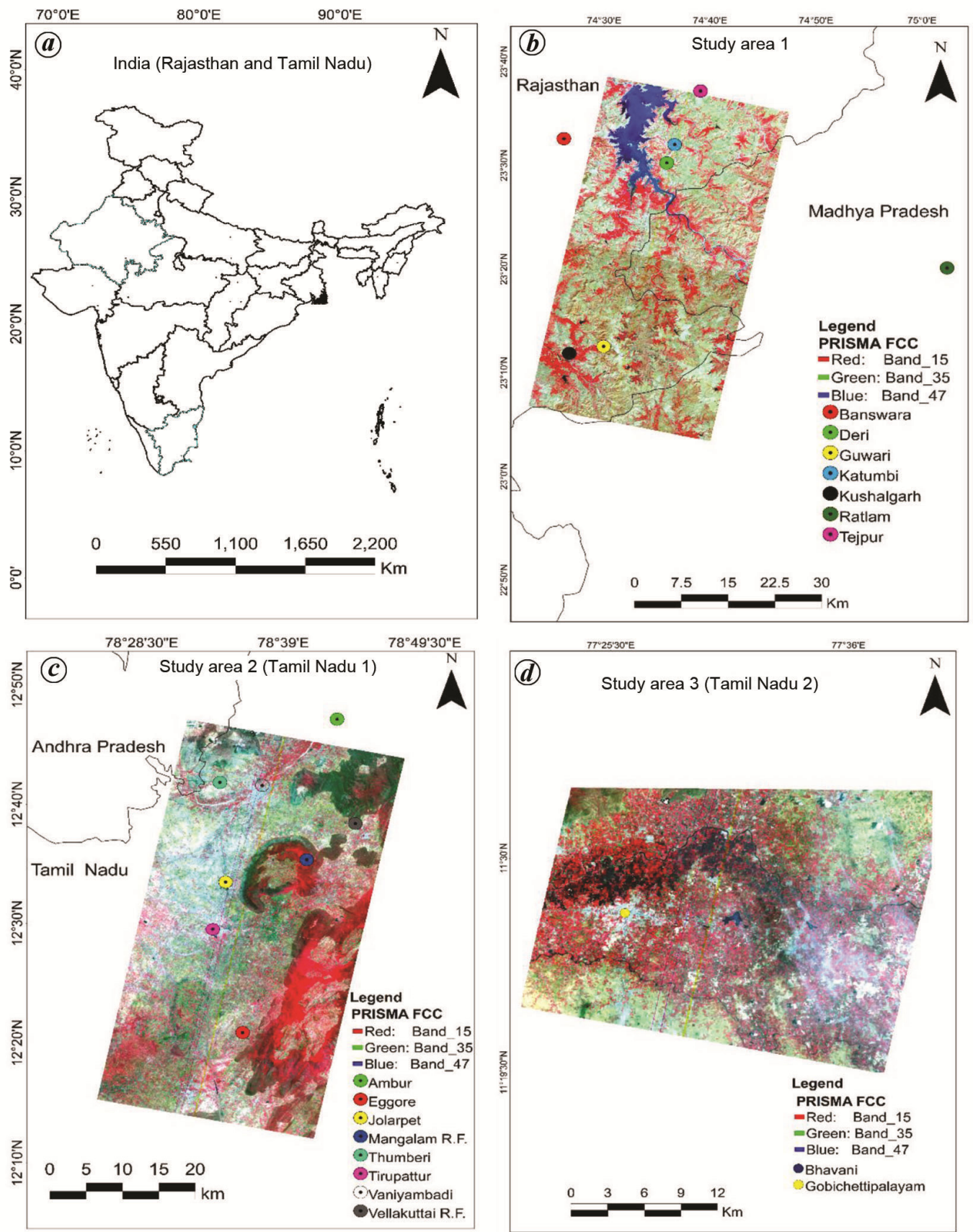

Figure 2. Study area (a) Rajasthan and Tamil Nadu (TN), India (source: Geological Survey of India). $\boldsymbol{b}$, Study area 1 covering Banswara district, Rajasthan and Ratlam distract, Madhya Pradesh, India; $\boldsymbol{c}$, Study area 2 or Tamil Nadu 1 covering Vaniyambadi and other towns, TN; $\boldsymbol{d}$, Study area 3 or Tamil Nadu 2 covering few areas of Erode district, TN and South Indian peninsula.

areas. PCA is essential for visualization of hyperspectral data through different dimensions so that detailed knowledge of the spectral properties of the desired targets is not required. Few of the PCA results with their geological importance are discussed after comparing with the lithological map and spectral absorption features from the literature ${ }^{24-30}$.

For study area 1 (Figure $5 a$ ), PC1 highlights majority of water bodies (Figure $5 b$ ), while PC2 gives a signifi- cant idea about the physiography and vegetation of the area (Figure $5 c$ ). PC2 shows the mineral areas as black patches. These patches are rocks of basalts and granite (Deccan traps) ${ }^{13,31}$. PC3 and PC5 represent the different textures of the surface (Figure $5 d$ and $e$ ). The colour composite of PC5, PC2 and PC1 gives a clear view of different types of rocks based on tone in the Banswara district. It classifies the upper area, including Katumbi, Tejpur, Deri and the lower area near Kushalgarh and 
REVIEW ARTICLES

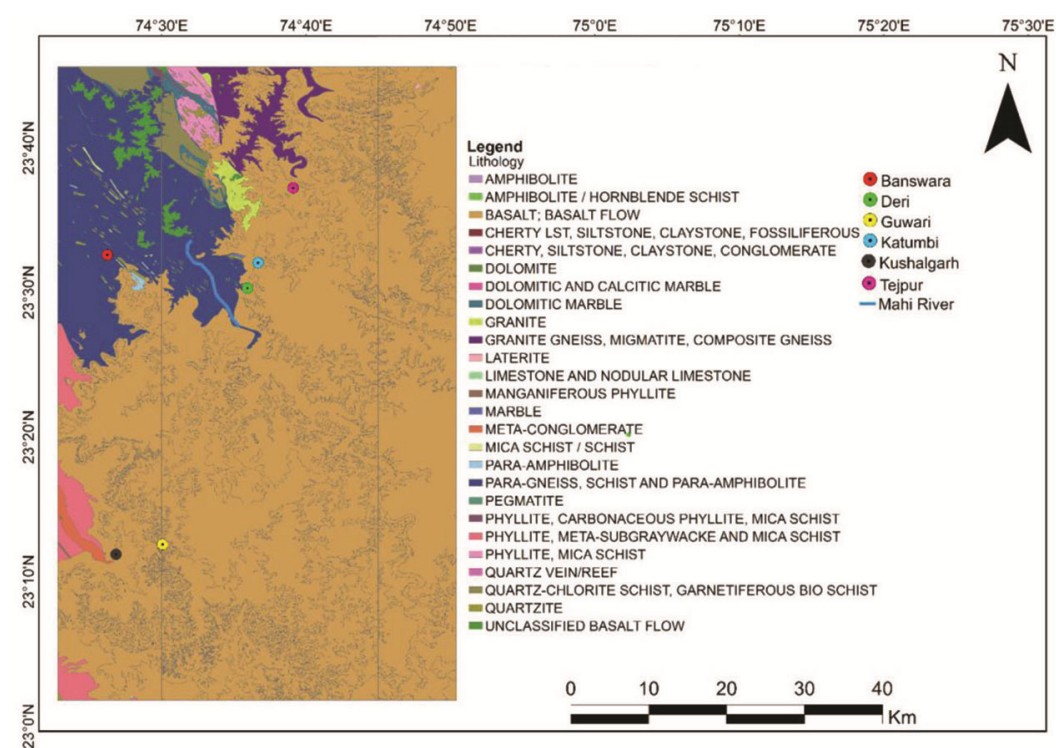

Figure 3. Lithological map for study area 1 (Rajasthan and Madhya Pradesh) (Source: GSI).
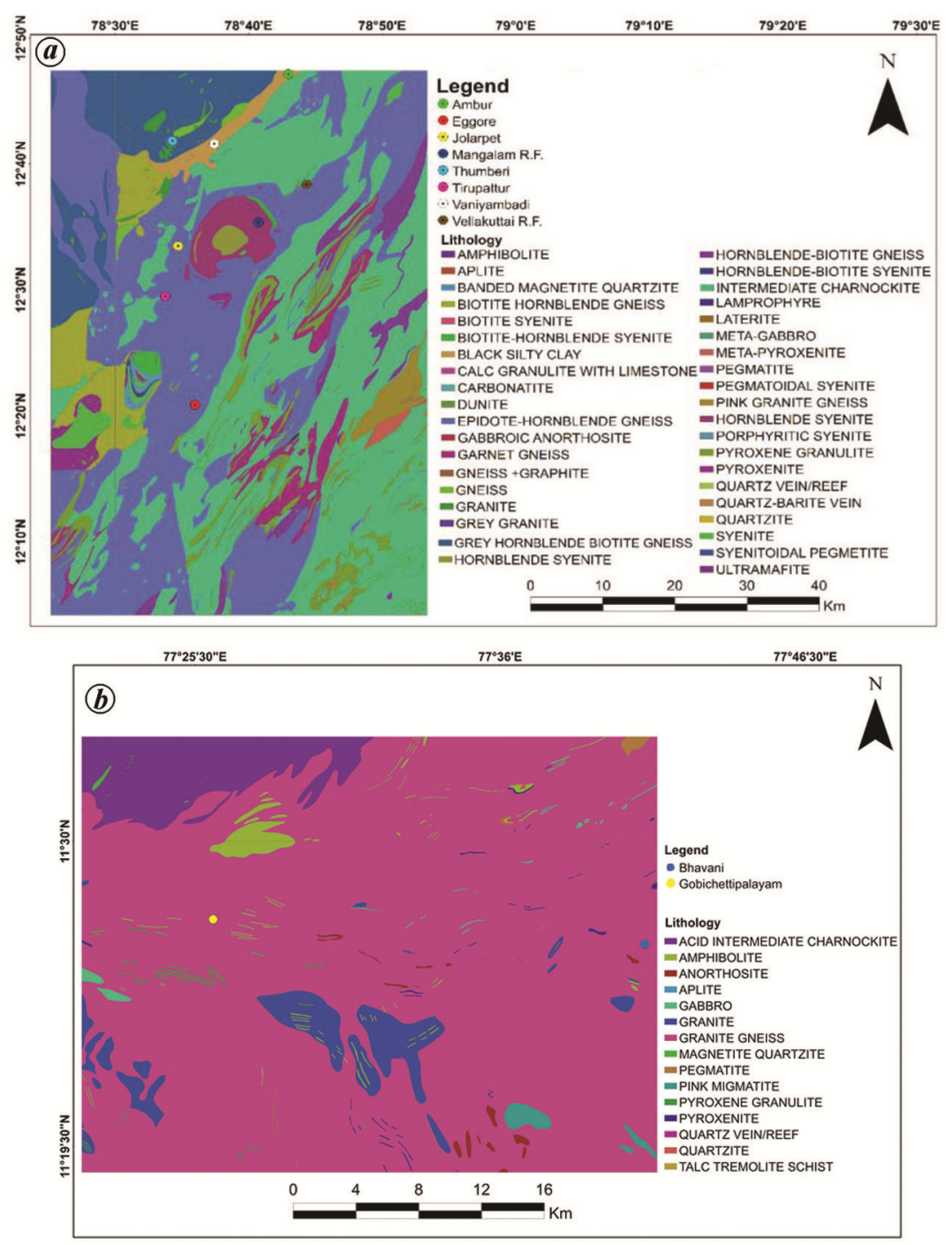

Figure 4. Lithological map for (a) study area 2 (Tamil Nadu 1) and (b) study area 3 (Tamil Nadu 2) (Source: GSI). 


\section{REVIEW ARTICLES}

Guwari, in different colours, which may be the alteration of biotite into chlorite in muscovite phyllite (Figure $5 f$ ). Other alteration minerals can be calcic-amphiboles, flattened albite and tourmaline ${ }^{32,33}$.

The study area 2 (Tamil Nadu 1), has a significant striping error in SWIR bands, which can be seen in different results (Figure 6). Two FCC images have been generated:

(i) $\mathrm{PC}$ indices $1: \mathrm{R}=\mathrm{PC} 1 \mathrm{G}=\mathrm{PC} 2 \mathrm{~B}=\mathrm{PC} 4$.

(ii) $\mathrm{PC}$ indices 2: $\mathrm{R}=\mathrm{PC} 3 \mathrm{G}=\mathrm{PC} 2 \mathrm{~B}=\mathrm{PC} 1$.

These colour composites aim to increase the spectral separation and enhance the interpretability of the data. The principal component reduces the redundancy, so FCC will be checked for various colours and shades of hilly features to discuss the geological importance (Figure $6 a$ ).

PC2 (Figure 6e) shows different results from PC1 (Figure $6 d$ ), which highlights the whole rock and hilly structure as one (bright), while PC2 showing the Mangalam Reserved Forest has different rock types from the Velakutta Reserve Forest. The other structure near Vaniyambadi differs from the rock structure visible in PC indices 1 (Figure $6 b$ ). The rocks and hills near Eggore and Mangalam Reserve Forests are visibly the same as the Velakutta Reserve Forest (Figure $6 c$ ). The rocks visible near Thumberi and Jolarpet are the same (Figure $6 f$ ). This implies that the minerals found here may belong to the same group. This area has mainly anorthosites, gneiss and orthopyroxene-bearing quartz-feldspar rocks ${ }^{34-36}$ (charnockites).

For the third study area 3 (Figure $7 a$ ) near Erode (Tamil Nadu 2), unfortunately, the upper part of the available tile was cropped because of cloud cover, but still few rock structures are visible in the top left part of the tile. The reason for selecting this area is the abundance of anorthosites ${ }^{37}$. Anorthosites are also found on the lunar surface ${ }^{38}$. The rock structure and soil type found here were used to derive lunar analogues ${ }^{39}$. A more definitive study of anorthosites in this region is now possible with PRISMA datasets. In Figure $7 d$ and $e$, PCA discriminates the urban features from natural features like vegetation. Two indices (Figure $7 b$ and $c$ ) are generated here:

(i) $\mathrm{PC}$ indices 1: $\mathrm{R}=\mathrm{PC} 1 \mathrm{G}=\mathrm{PC} 2 \mathrm{~B}=\mathrm{PC} 3$.

(ii) $\mathrm{PC}$ indices 2: $\mathrm{R}=\mathrm{PC} 3 \mathrm{G}=\mathrm{PC} 4 \mathrm{~B}=\mathrm{PC} 2$.

The clouds are visible in PC indices 2 and PC4 (Figure $7 f)$.

\section{Spectral analysis}

The main objective of spectral analysis is to check the spectral accuracy of PRISMA for different earth-surface features. Spectra are extracted at a few places for study area 1 (Figure $8 a$ ), according to the lithological
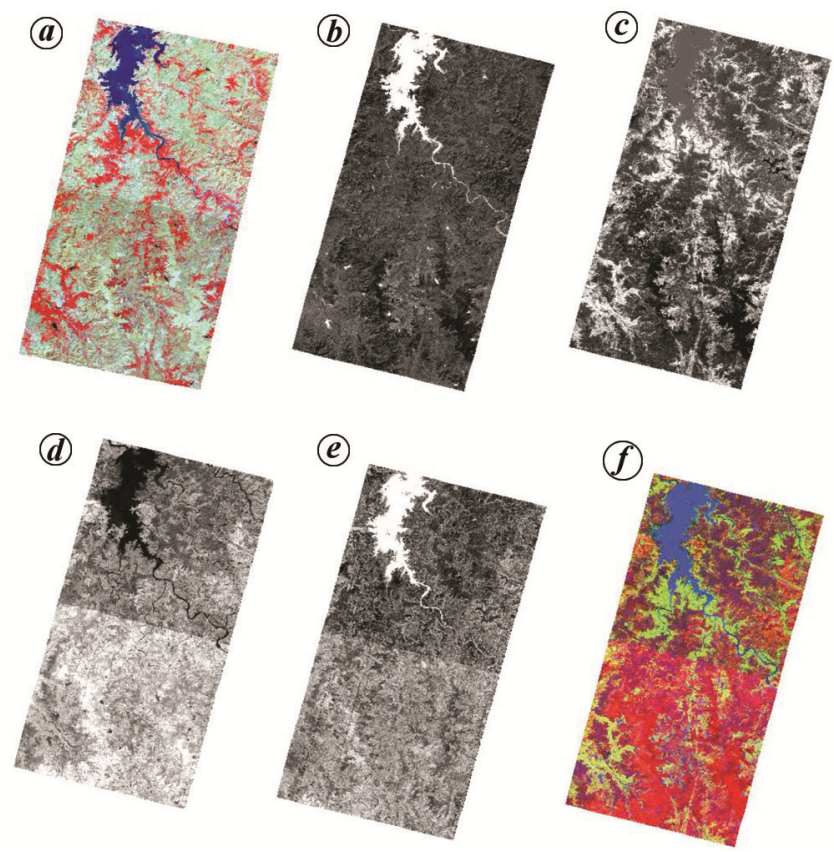

Figure 5. Principal component analysis (PCA) for study area 1. a, PRISMA FCC for Rajasthan area with R: band 15, G: band 35, B: band $47 ; \boldsymbol{b}, \mathrm{PC} 1 ; \boldsymbol{c}, \mathrm{PC} 2 ; \boldsymbol{d}, \mathrm{PC} 3 ; \boldsymbol{e}, \mathrm{PC} 5 ; \boldsymbol{f}$, Colour composite with R: PC5, G: PC2, B: PC1.
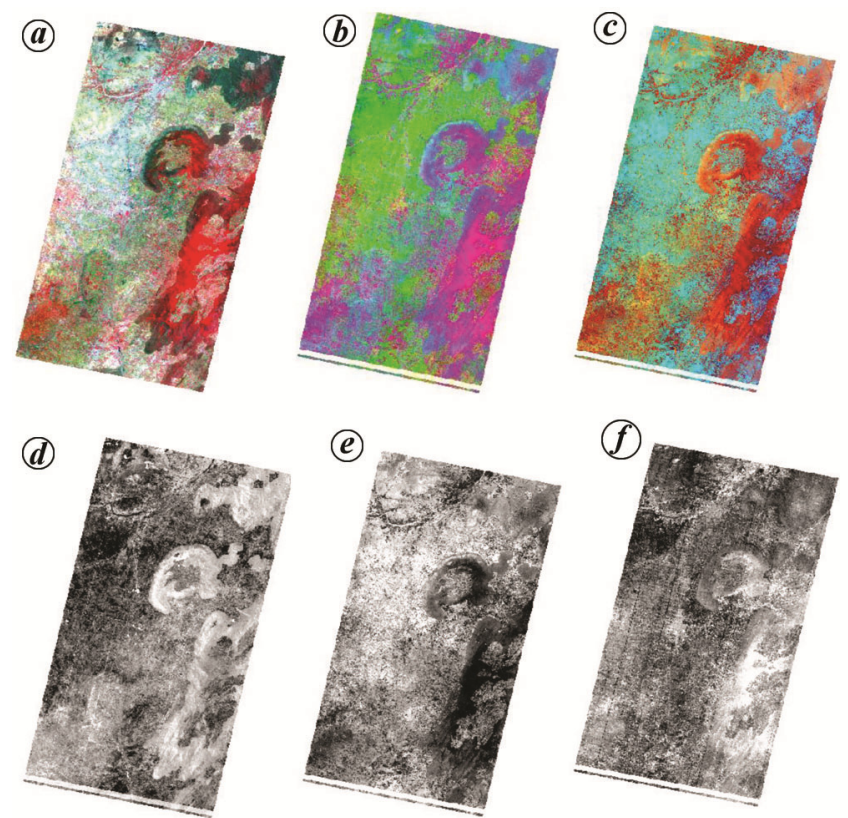

Figure 6. PCA for study area 2 with striping error in the SWIR band on the lower part of the image. a, PRISMA false-colour composite (FCC) for Tamil Nadu area; $\boldsymbol{b}, \mathrm{PC}$ indices $1 ; \boldsymbol{c}$, PC indices 2; $\boldsymbol{d}$, PC1; $\boldsymbol{e}, \mathrm{PC} 2 ; \boldsymbol{f}, \mathrm{PC} 3$. 
map $^{31}$, and spectral absorption features from the literature ${ }^{24-28,30,40}$. The variation in absorption features is noticed (Figure $8 \mathrm{~b}$ ). Some absorption features are found at 710,930,1174, 1533, 1687, 2010-2080, 2077 and $2175 \mathrm{~nm}$. These show the presence of hydroxyl and iron oxides. The various absorption features were observed mainly due to quartzite, mica schist, conglomerates, phyllites, gneiss and intrusives such as granites and amphibolite ${ }^{41,42}$. The characterization and identification of these absorption features is possible due to the availability of such bands in the VNIR and SWIR regions.

Similar spectral analysis was carried out for study areas 2 and 3. For Tamil Nadu 1, a $W$ shaped absorption feature was visible at 1110-1152 nm with a sharp dip at

Table 4. Absorption features observed in VNIR and SWIR $\operatorname{range}^{26-28,30,40,47,61,62}$

\begin{tabular}{ll}
\hline Wavelength $(\mathrm{nm})$ & \multicolumn{1}{c}{ Molecule/ion } \\
\hline $340-430$ & Manganese, chromium, ferric, nickel \\
450 & Ferrous, manganese, chromium \\
500 & Ferric, argillized rocks \\
550 & Ferrous, chromium \\
$570-950$ & Ferrous/ferric, nickel, argillized rocks \\
1000 & OH, ferrous, olivine, pyroxene \\
$1070-1200$ & Ferrous \\
$1300-1550$ & OH/ $\mathrm{H}_{2} \mathrm{O}$, opalized rocks \\
$1600-1900$ & Organic material, ferrous, carbonates, $\mathrm{H}_{2} \mathrm{O}$ \\
1950 & $\mathrm{H}_{2} \mathrm{O}$, ferrous \\
$2000-2160$ & Carbonates, ferrous \\
2200 & Al-OH, opalized rocks, argillized rocks, phyllite, \\
& quartzite, felsite \\
2250 & OH, Mg-OH \\
2300 & Carbonates, Fe-OH, Mg-OH, silicified rocks, \\
& opalized rocks, limestone, phyllite, organic \\
& material \\
2350 & Carbonates \\
2400 & Carbonates, felsite \\
\hline & Mg-OH \\
\hline
\end{tabular}
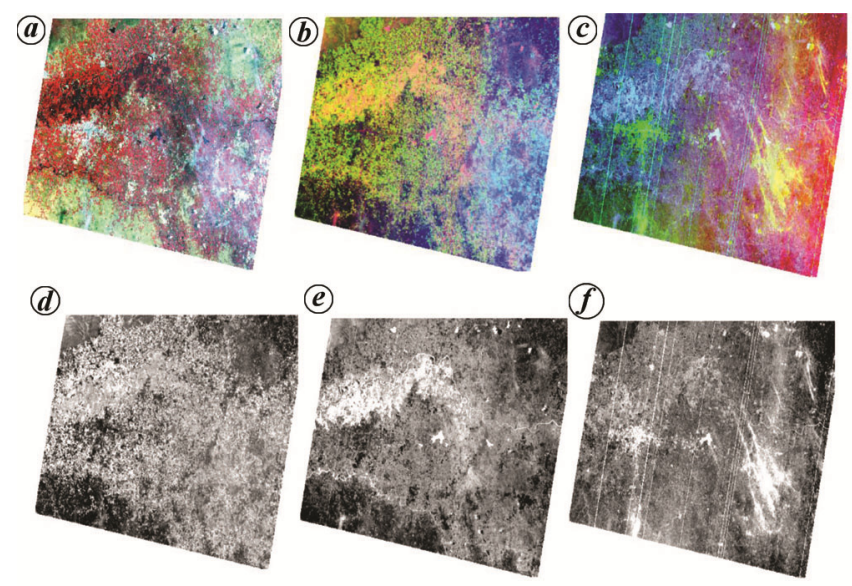

Figure 7. PCA for study area 3 with clouds. a, PRISMA FCC for Tamil Nadu $2 ; \boldsymbol{b}, \mathrm{PC}$ indices $1 ; \boldsymbol{c}, \mathrm{PC}$ indices $2 ; \boldsymbol{d}, \mathrm{PC} 1 ; \boldsymbol{e}, \mathrm{PC} 2$; $\boldsymbol{f}$, PC4.
$1667 \mathrm{~nm}$ (Figure $9 \mathrm{~b}$ ). This may be due to the presence of charnockite as many of the absorption features at 930 980, 1120-1152 and 200-2300 nm are matched with the field spectra obtained by Ahmad et al. ${ }^{43}$, which also says that pyroxene is responsible for the diagnostic absorption feature around 1000 and $2000 \mathrm{~nm}$. The sharp absorption features at $900-1000 \mathrm{~nm}$ could be due to the higher percentage of pyroxene minerals in the area ${ }^{44}$. It was found in a few studies that charnockite contains orthopyroxene, quartz and feldspar ${ }^{29,45,46}$. Study areas 1 and 2 had a few identical spectral absorption features ${ }^{47}$ at $900-1000$ and 2200-2300 nm, highlighting the presence of hydroxyl (1300-1400 and 1900-2000 nm), ferrous/ferric ions and carbonates $^{24,26-28,40}$.

The study area 3 (Tamil Nadu 2) has a very less geological part (Figure $10 a$ ). Some spectra are extracted from the rocks visible in the study area with no significant absorption features other than the hydroxyl ions (Figure $10 b$ ).

A summary of the absorption features obtained from all the study areas is given in Table 4 , with their possible causes.

\section{Savitzky-Golay smoothing}

Sometimes atmospheric error and errors due to electronics and optics of sensor result in spikes in the spectra. The Savitzky-Golay smoothing technique is a kernelbased method that reduces the noise, such as spikes in datasets. It fits a least-square polynomial to the moving kernel on uniformly spaced spectrum data ${ }^{48}$. This type of smoothing is also used with higher-order derivatives. Smoothing parameters can be changed according to the nature of the data (Figure $11 a$ ). A very large number of sampling intervals in Savitzky-Golay technique can suppress the important spectral features by oversmoothening. Here polynomial order 3 with interval 8 is applied on a spectrum extracted from study area 2 , because the higher-order derivative always had a large number of closely spaced spikes (Figure $11 \mathrm{~b}$ ).

\section{Derivative spectroscopy}

Derivative spectroscopy can help mitigate spectra-related problems like the resolution of multicomponent functions and background noise. It can enhance the microscopic spectral features to distinguish the look-alike spectra in optical and thermal wavelength regions ${ }^{49}$. For a secondorder derivative, eq. (1) can be used.

$$
\frac{\mathrm{d}^{2} A}{\mathrm{~d} \lambda^{2}}=f^{\prime \prime}(\lambda)=\frac{A_{(\lambda-\Delta \lambda)}-2 A_{(\lambda)}+A_{(\lambda+\Delta \lambda)}}{\Delta \lambda^{2}},
$$

where $A$ is the absorbance and $\lambda$ is the wavelength.

The peaks and dips in the original spectra will become dips and peaks after the second-order derivative 

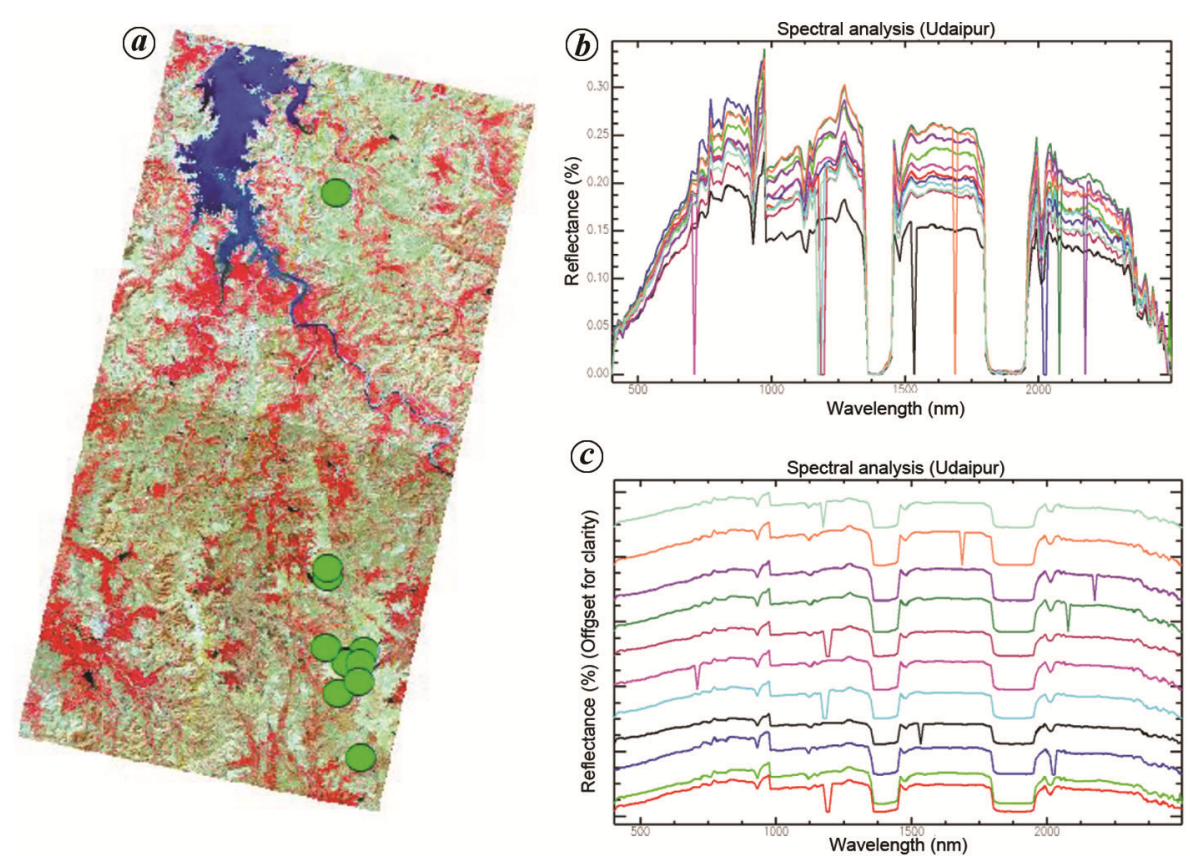

Figure 8. Spectral analysis for study area 1. $\boldsymbol{a}$, PRISMA FCC with green dots showing the location of spectra extracted. $\boldsymbol{b}$, Spectra obtained. $\boldsymbol{c}$, Spectra stacked for clarity.
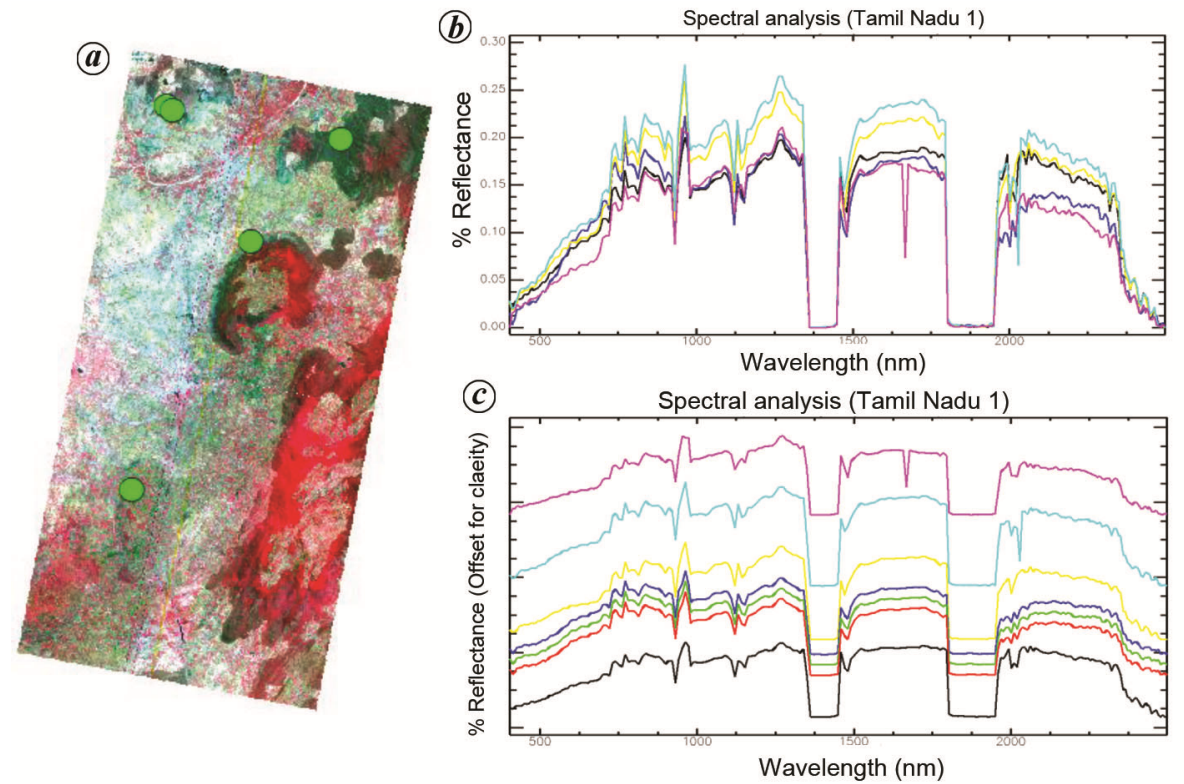

Figure 9. Spectral analysis for study area 2. a, PRISMA FCC with green dots showing the location of spectra extracted. $\boldsymbol{b}$, Spectra obtained. $\boldsymbol{c}$, Spectra are stacked for clarity.

(reciprocity). Smoothing is also applied to remove the unwanted spikes. Figure 12 shows the unresolved dips around $1800-1900 \mathrm{~nm}$. Also, the exact position of absorption features can be obtained.

\section{Narrowband indices}

Few narrowband indices have been modified and generated for the study area 2 (Table 5). Normalized difference soil index (NDSI) discriminates between the soil and vegetation based on reflectance value. Figure $13 a$ shows an area with majority of soil. Modified soil-adjusted vegetation index (MSAVI) (Figure 13b) diminishes the background influence using the canopy background adjustment factor. The modified desertification soil index (MDSI), which uses three different wavelengths (1648, 498 and $2300 \mathrm{~nm}$ ), represents the access soil desertification. Desertification of soil is represented by higher 

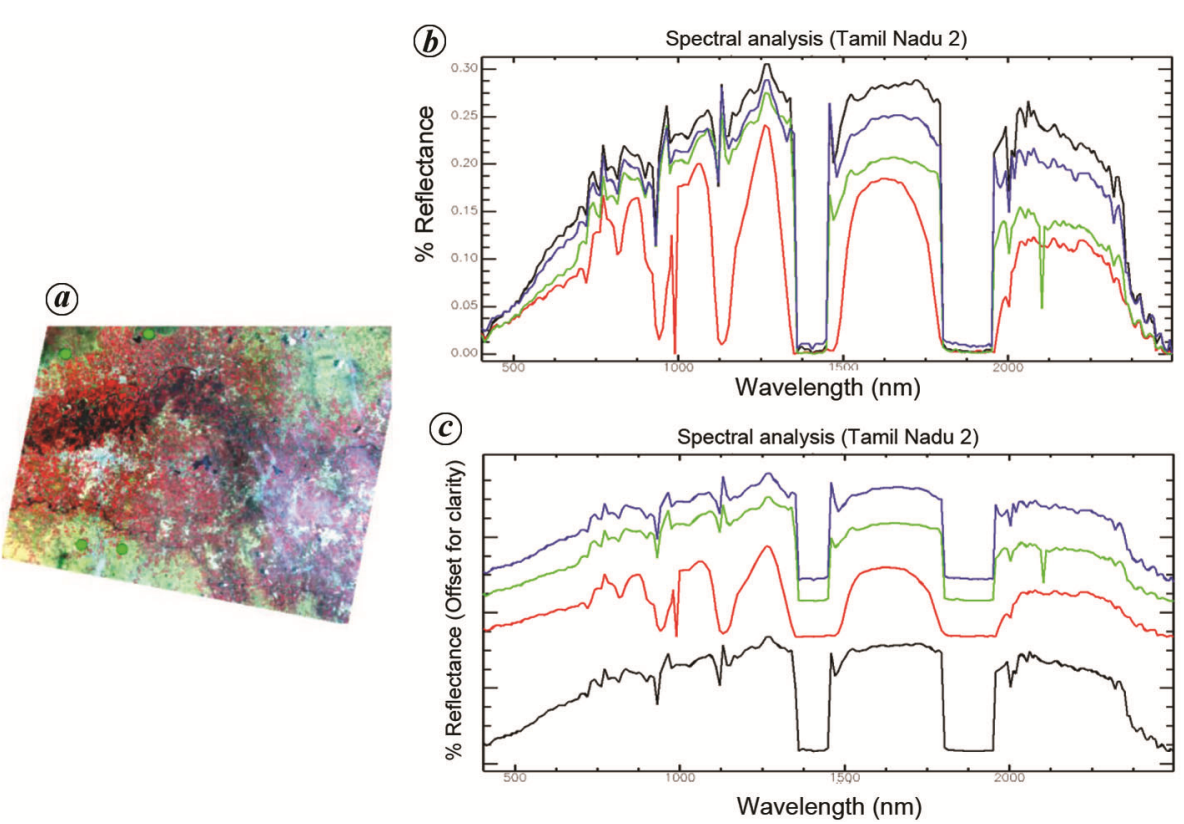

Figure 10. Spectral analysis for study area 3. a, PRISMA FCC with green dots showing the location of spectra extracted. $\boldsymbol{b}$, Spectra obtained. $\boldsymbol{c}$, Spectra stacked for clarity.
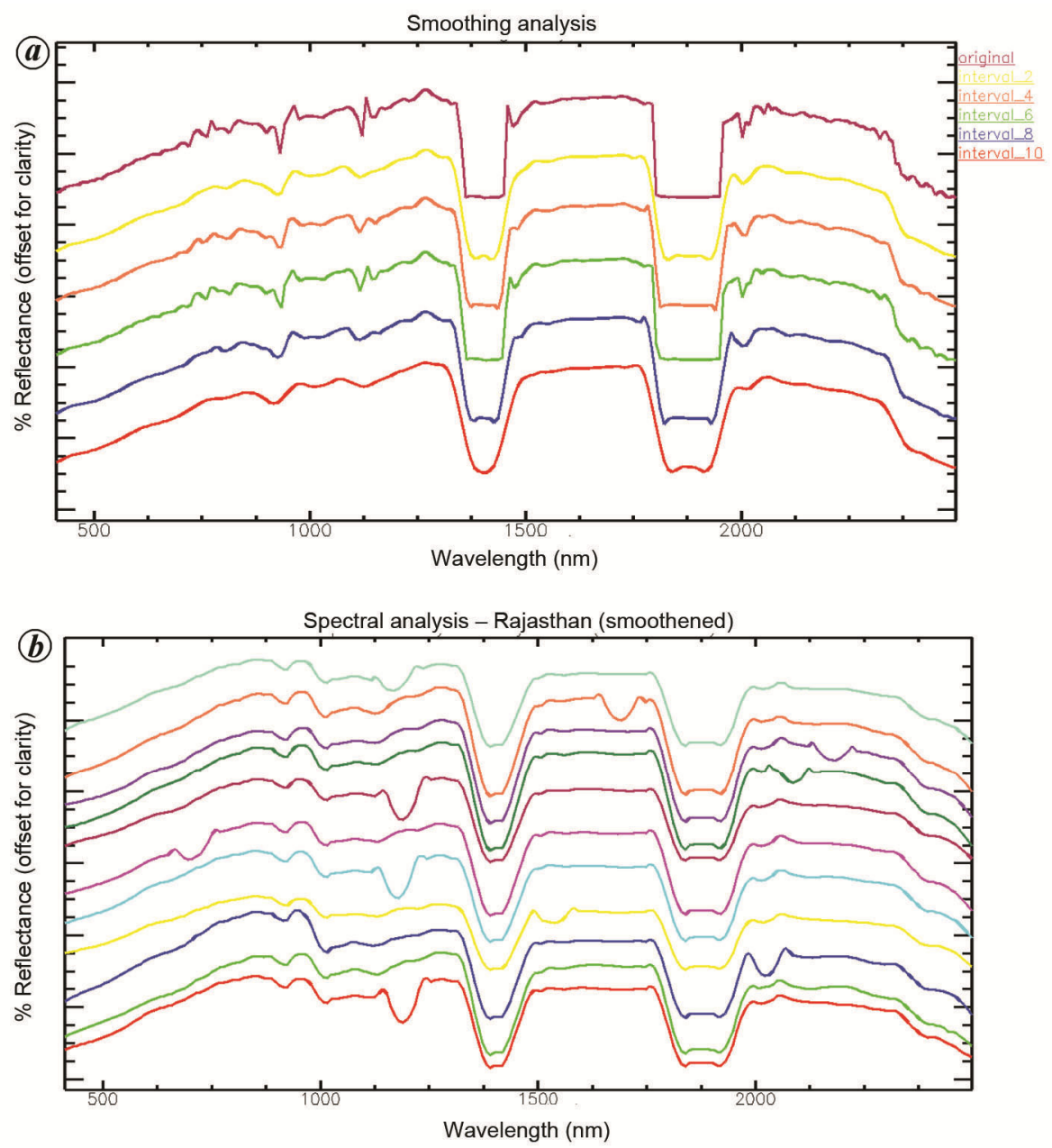

Figure 11. Savitzky-Golay smoothing. $\boldsymbol{a}$, Smoothing with different intervals (maroon $=$ original, yellow $=$ interval 2 , coral $=$ interval 4 , green $=$ interval 6 , blue $=$ interval 8 , red $=$ interval 10$). \boldsymbol{b}$, Smoothing with polynomial order 3 and interval 8 applied on the spectra extracted from study area 1 . 


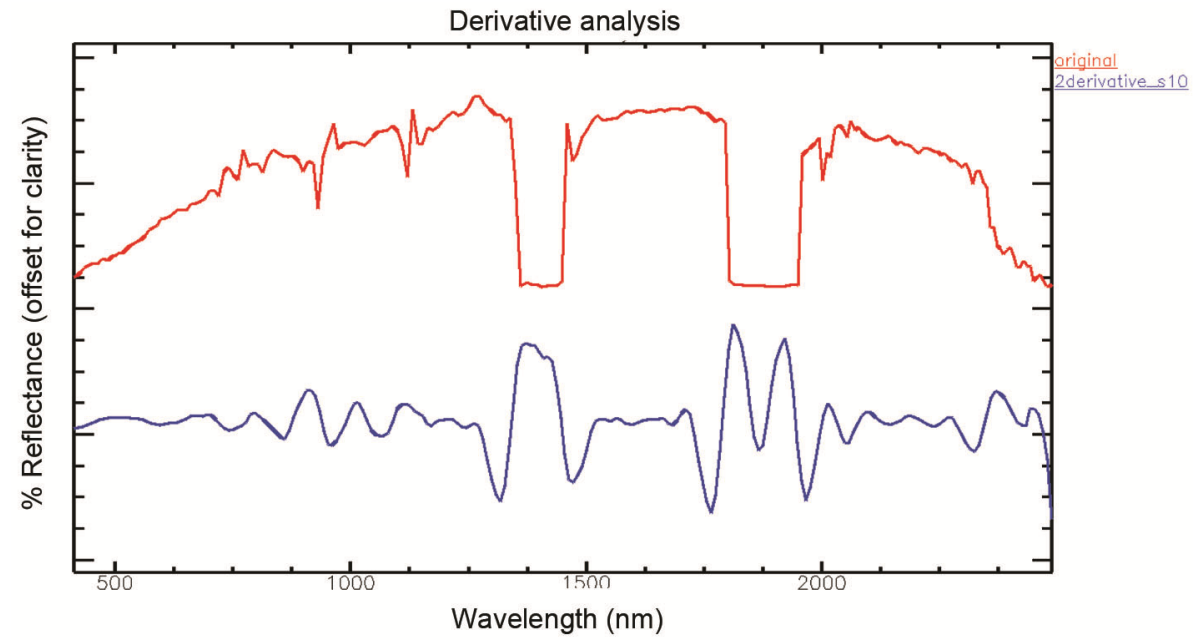

Figure 12. Second-order derivative with smoothing applied on spectra obtained from study area 1 $($ red $=$ original, blue $=$ second-order derivative with smoothing interval 10$)$.

Table 5. Band ratio/indices used in the study

\begin{tabular}{|c|c|c|}
\hline & Original band ratio/indices & Band ratio/indices for PRSIMA \\
\hline Normalized difference soil index (NDSI) ${ }^{63}$ & $\frac{R_{1650}-R_{650}}{R_{1650}+R_{650}}$ & $\frac{R_{1647}-R_{652}}{R_{1647}+R_{652}}$ \\
\hline \multirow[t]{2}{*}{ Modified soil adjusted vegetation index (MSAVI) ${ }^{64}$} & $2 \mathrm{NIR}+1-\sqrt{(2 \mathrm{NIR}+1)^{2}}-8(\mathrm{NIR}-\mathrm{RED})$ & $2 R_{803}+1-\sqrt{\left(2 R_{803}+1\right)^{2}-8\left(R_{803}-R_{671}\right)}$ \\
\hline & 2 & 2 \\
\hline \multirow[t]{2}{*}{ Modified desertification soil index ${ }^{50}$} & $R_{1648}-R_{498}$ & $R_{1647}-R_{501}$ \\
\hline & $\overline{R_{1648}-R_{2203}+0.2}$ & $\overline{R_{1647}-R_{2206}+0.1}$ \\
\hline \multirow[t]{2}{*}{ Kaolinite band ratio ${ }^{65}$} & (Band $4+$ Band $6+$ Band 9 & $R_{1647}+R_{2206}+R_{2260}$ \\
\hline & Band 5 & $R_{2167}$ \\
\hline \multirow[t]{2}{*}{ Amphibole band ratio ${ }^{66}$} & Band $6+$ Band 9 & $\underline{R_{1647}+R_{2400}}$ \\
\hline & Band 8 & $R_{2342}$ \\
\hline \multirow[t]{2}{*}{ Modified clay and iron band ratio ${ }^{67}$} & Band $5 \times$ Band 7 & $R_{2167} \times R_{2260}+R_{2167}$ \\
\hline & $(\text { Band 6) })^{2}$ & $\left(R_{2206}\right)^{2}+\frac{R_{1647}}{R_{1}}$ \\
\hline
\end{tabular}

reflectance values ${ }^{50}$. Figure $13 d$ shows the abundance of kaolinite formed by chemical weathering of aluminium silicate minerals like feldspar. This may be due to weathering and fracturing of charnockites ${ }^{51}$. Figure $13 e$ shows the amphibole, which is also related to feldspar. Clay and iron indices include the additional term with spectral bands at 2165 and $1650 \mathrm{~nm}$, to indicate the presence of iron. As seen in Figure $13 f$, clay and iron are present in abundance in the whole Vaniyambadi region.

\section{Comparison of spectral profile from PRISMA and Hyperion}

The coverage of PRISMA is greater than that of Hyperion (Figure 14). The absorption features for vegetation and minerals were compared for PRISMA and Hyperion with the USGS spectral library ${ }^{52}$ (Figure 15). The Hyperion (EO-1) was launched ${ }^{53}$ in 2000 and decommissioned ${ }^{54}$ in 2017. The Hyperion datasets used here are from October 2015 for Rajasthan; March 2004 and February 2019 for Tamil Nadu, while both PRISMA datasets were acquired in February 2020. The spectra are taken with spatial reference to the lithological map (Figures 3 and 4). The diagnostic absorption features of the vegetation and charnockite rocks obtained from PRISMA, matched more precisely with the USGS reference spectra. For charnockite, the USGS spectra of diopside and augite were taken as reference because of similar diagnostic features at $800-1000$ and $2300 \mathrm{~nm}$ (Figure $15 \mathrm{~b})^{43}$. The vegetation spectra from Hyperion had more spikes between 800 and $1000 \mathrm{~nm}$ than PRISMA (Figure $15 \mathrm{a}$ ). Higher SNR for VNIR and SWIR bands for PRISMA yields a better spectral profile of various earth materials. 


\section{Unsupervised classification}

Here unsupervised classification technique is used for both study areas to check the spectral strength of the datasets. Although it is elementary to classify the minerals using supervised techniques, we want to highlight the strength of PRISMA datasets in classifying minerals based on statistics only. It may be the best way to find all the unknown patterns in the data. In unsupervised classification, pixels are grouped into 'clusters' based on their properties. These clusters can be named as 'classes'. The algorithms used here are the $K$-means and iterative selforganizing data analysis technique algorithm (ISODATA) clustering. The difference between both classification techniques is that the number of clusters is known earlier in $K$-means, while ISODATA algorithm allows iteration for the different number of clusters ${ }^{55}$. It also refines the classes by splitting and merging clusters based on pixels and standard deviation ${ }^{56}$. $K$-means classification algorithm is used for the study area 1 (Figure 16). On comparing the classified image with the lithological map of the study area 1 , class 2 is matched with basalts flow, class 3 as phyllite, class 4 is assigned as mica schist, basaltic minerals and gneiss. Class 1 belongs to the water body, although there are few pixels of class 1 (red) over the region, which maybe because of bias. Class 5 (cyan) represents mixed minerals.

For Tamil Nadu region (study area 2) the ISODATA classification algorithm was used (Figure 17). Compared with the lithological map, biotite hornblende gneiss, acid to intermediate charnockite and porphyritic hornblende syenite are classified as class 3,2 and 1. However, there is a mix-up between classes 1 and 4. It is observed from both classification results that PRISMA offers a better classification of abundant minerals in the selected regions.

\section{Challenges and recommendation}

This new dataset is adequate for research, but there are a few shortcomings. The band indexing for VNIR and SWIR bands is in reverse order ${ }^{5}$. The use of Python and other programing languages is recommended. The stacking of VNIR and SWIR will be possible in ENVI software after georeferencing. The reflectance value should be converted to percentage reflectance for spectral analysis. The datasets have striping error (Figure 18) which can hamper the accuracy of classification and PCA analysis; so the use of spatial pixel editor and other averaging methods is recommended.

\section{Discussion}

One of the significant challenges in imaging spectroscopy is to identify and characterize minerals, vegetation and waterbodies. PRISMA is a cutting-edge new-generation
Earth observation mission. This study has demonstrated the validity of various image-processing techniques. The dimensionality reduction method, based on variance, enhances the details from the hyperspectral dataset and hence can be of considerable significance to mineralogists. Spectral analysis, one of the most advanced remotesensing techniques, was utilized as a potential method of identifying the mineralogy. Moreover, the spectral performance is satisfactory for all features types. The different diagnostic features observed in VNIR and SWIR spectral bands are responsible for the identification and
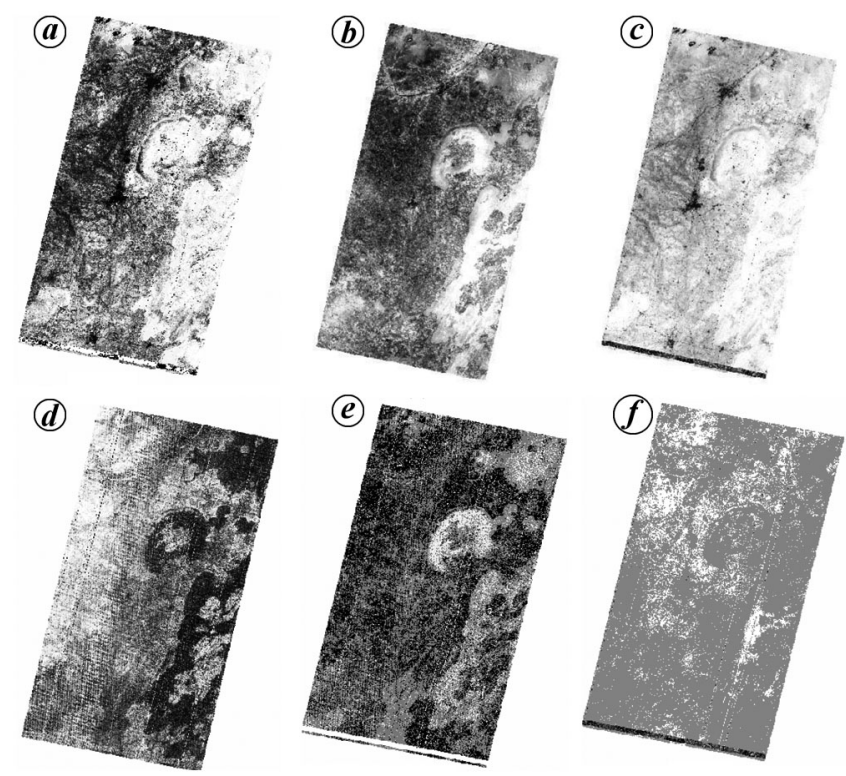

Figure 13. Narrowband ratios and indices generated for study area 2 (Tamil Nadu 1). $\boldsymbol{a}$, NDSI; $\boldsymbol{b}$, MSAVI; $\boldsymbol{c}$, MDSI; $\boldsymbol{d}$, Kaolinite band ratio; $\boldsymbol{e}$, Amphibole band ratio; $\boldsymbol{f}$, Modified clay and iron ratio.
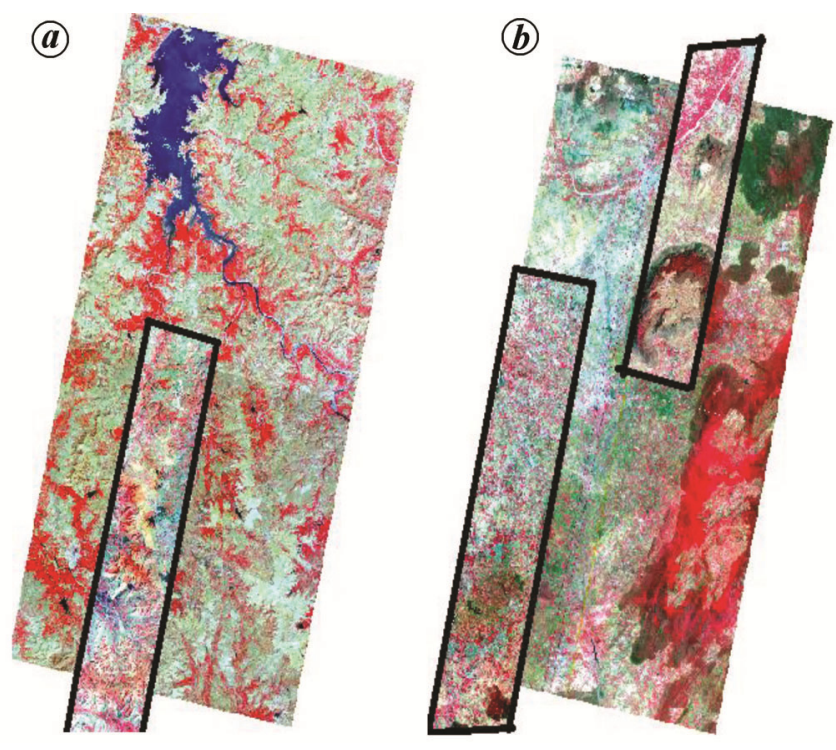

Figure 14. Hyperion and PRISMA datasets overlay for (a) study area 1 and (b) study area 2. 
(a)

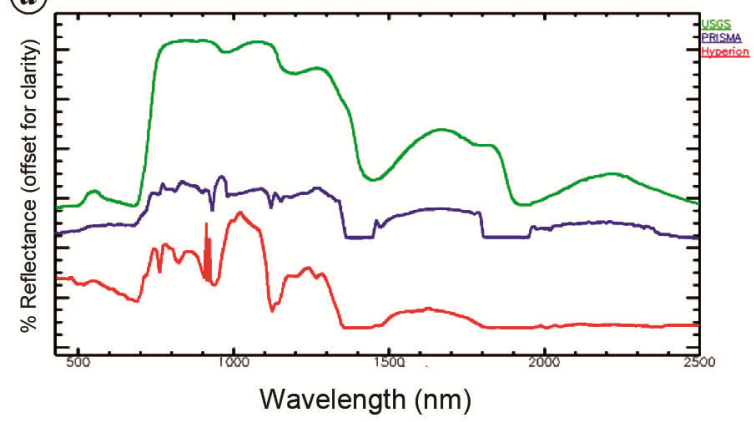

(b) Spectral profile comparison for chamockite

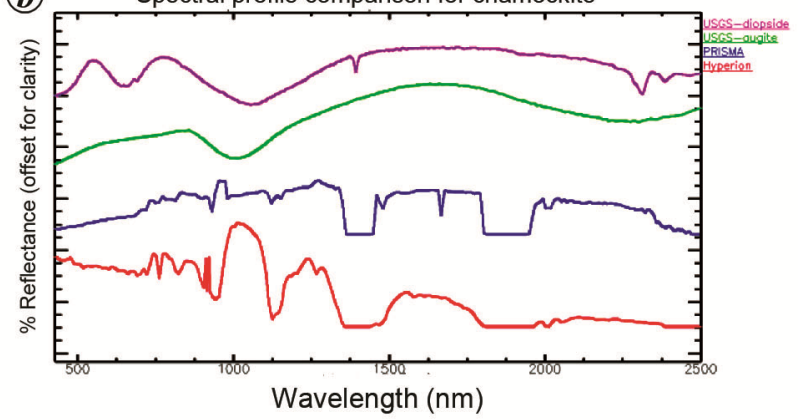

Figure 15. Comparison of spectra extracted from the same location for Hyperion and PRISMA with USGS spectra. (a) Vegetation and $(\boldsymbol{b})$ charnockite $($ red $=$ Hyperion, blue $=$ PRISMA, green $=$ USGS, magenta $=$ USGS).

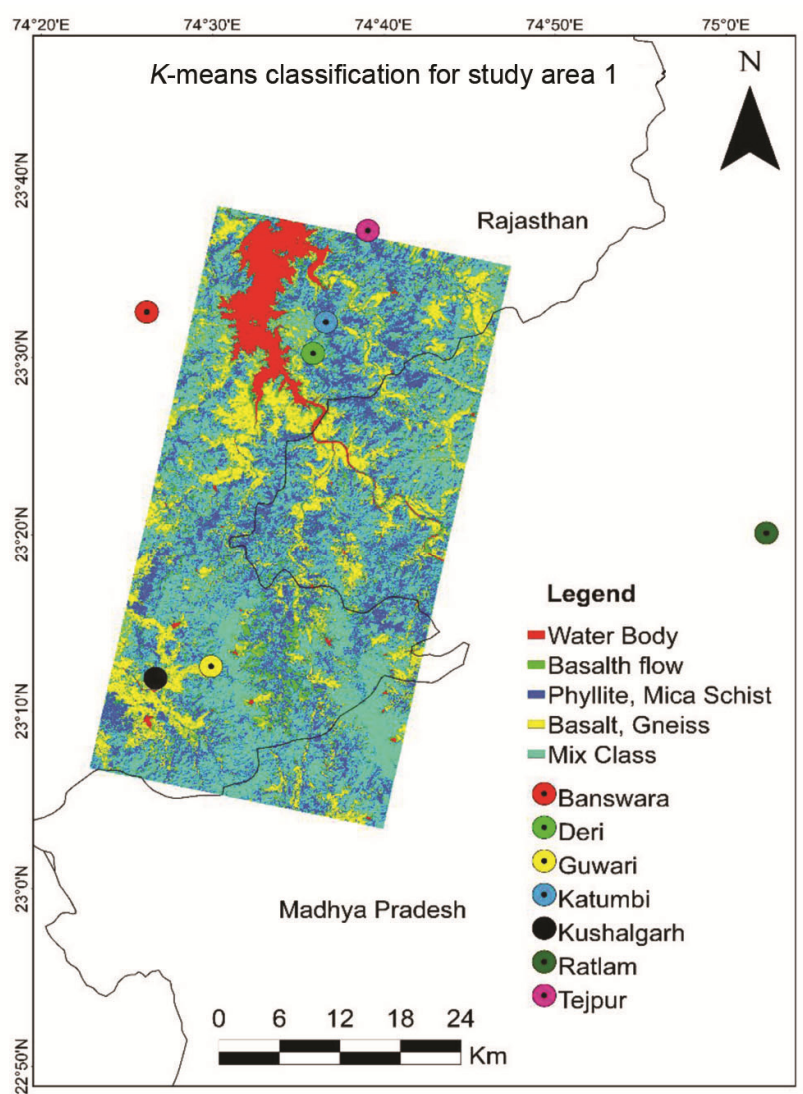

Figure 16. K-means classification for study area 1.

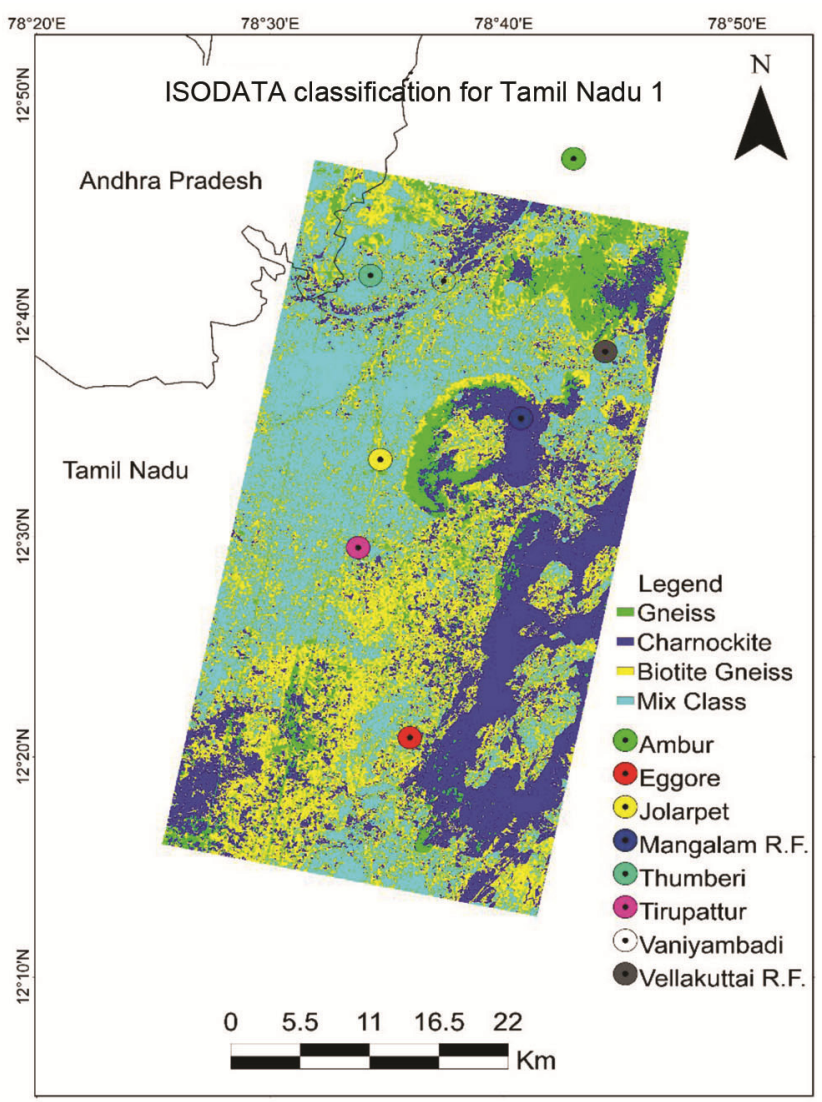

Figure 17. ISODATA classification for study area 2.

characterization of the silicate group of minerals. Microwave imagery can also be fused with hyperspectral datasets in mid-infrared range (1550-2350 nm) for delineation of hydrothermally altered zones, lithological discrimination, soil moisture, flood mapping and geothermal mapping.

Various lunar analogue studies have been done earlier using an Earth-based hyperspectral sensor. PRISMA satellite data with better SNR and swath can also be used in place of Hyperion to study the lunar analogues by integrating spectral information from the data acquired by 


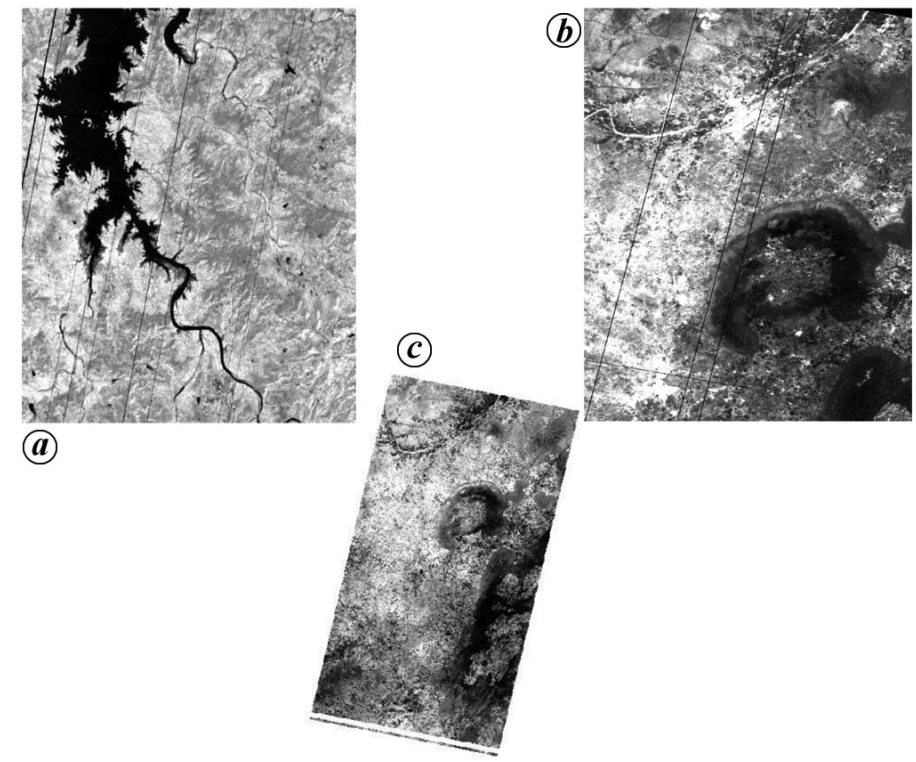

Figure 18. Striping error in PRISMA hyperspectral datasets. $\boldsymbol{a}$, striping error in band 235 (SWIR) of study area 1. $\boldsymbol{b}$, striping error in band 57 (VNIR) of study area 2. $\boldsymbol{c}$, A wide striping error in band 94 (SWIR) at the bottom of the image.

a previous lunar mission like Apollo or the hyperspectral sensor like Moon Mineralogy Mapper $\left(\mathrm{M}^{3}\right)$ on-board ISRO's Chandrayaan-1 spacecraft.

The present study focuses on the first detailed report of the spectral ability of PRISMA hyperspectral sensor. There are many hyperspectral data analysis techniques, i.e. data fusion, unmixing, classification, target detection, physical parameter retrieval, fast computing, signal and image processing, statistical methods and machine learning. With these techniques PRISMA hyperspectral data will prove to be a boon for scientists and researchers in the field of hyperspectral remote sensing.

\section{Conclusion}

PRISMA is a vital earth observation mission that will provide crucial high-quality hyperspectral data products globally. Researchers in geology, forestry, marine science, agriculture, soils, and other application fields will be the end-user of the datasets to develop new algorithms and applications. The work done in this paper has demonstrated the initial impressions, showing the capability of PRISMA hyperspectral datasets for the geological applications using various statistical techniques.

1. Loizzo, R. et al., Prisma Mission Status and Perspective. In IGARSS 2019 - 2019 IEEE International Geoscience and Remote Sensing Symposium, Yokohama, Japan, 2019, pp. 4503-4506.

2. Griffin, M. K., May-Hsu, S., Burke, H. K., Orloff, S. M. and Upham, C. A., Examples of EO-1 Hyperion data analysis. Lincoln Lab. J., 2005, 15, 271-298.

3. Guanter, L., Alonso, L. and Moreno, J., First results from the PROBA/CHRIS hyperspectral/multiangular satellite system over land and water targets. IEEE Geosci. Remote Sensing Lett., 2005, 2, 250-254

4. Mahalingam, S. et al., Reflectance based vicarious calibration of HySIS sensors and spectral stability study over pseudo-invariant sites. In Proceedings of the 2019 IEEE Recent Advances in Geoscience and Remote Sensing: Technologies, Standards and Applications, TENGARSS 2019, Institute of Electrical and Electronics Engineers Inc., Kerala, India, 2019, pp. 132-136.

5. Italian Space Agency, PRISMA User Manual, 2020; http://prisma-i. it/index.php/en/ (accessed on 15 June 2020).

6. Loizzo, R. et al., Prisma: the Italian hyperspectral mission. In International Geoscience and Remote Sensing Symposium (IGARSS), Institute of Electrical and Electronics Engineers Inc., Valencia, Spain, 2018, pp. 175-178.

7. Galeazzi, C., Sacchetti, A., Cisbani, A. and Babini, G., The PRISMA program. Internaitnal Geoscience Remote Sensing Sympium, Boston, MA, 2008, vol. 4, pp. 105-108.

8. Italian Space Agency, PRISMA Data Policy, 2020; http://prisma-i. it/index.php/en/ (accessed on 15 June 2020).

9. Contini, C., PRISMA Space Segment. In First National Workshop on Data Exploitation of PRISMA Mission Precursor of National Hyperspectral Space Mission Italian Space Agency (ASI), Rome, Italy, 2007, pp. 1-12.

10. Italian Space Agency, PRISMA Products Specification Document. Rome, Italy, 2020, pp. 1-262; http://prisma.asi.it/missionselect/ docs.php (accessed on 15 June 2020).

11. Crosta, A. P. and Moore, J. M., Rehancement of LANDSAT Thematic Mapper imagery for residual soil mapping in SouthWest Minas Gerais State, Brazil: A prospecting case history in Greenstone Belt terrain. In Thematic Conference Remote Sensing Exploration of Geol. Methods, Integral Solutions 7, Environmental Research Institute, Michigan, Ann Arbor, 1990, pp. 11731187.

12. Loughlin, W. P., Principal component analysis for alteration mapping. Photogramm. Eng. Remote Sensing, 1991, 57, 1163-1169.

13. Naqvi, S. M. and Rogers, J. J. W., Precambrian Geology of India, Oxford University Press, California, 1987.

14. Gupta, B. C., The Geology of Central Mewar, Office of the Geological Survey of India, New Delhi, 1934. 


\section{REVIEW ARTICLES}

15. Heron, A. M., The pre-Vindhyan geology of Rajputana. Curr. Sci., 1935, 4(2), 83-88.

16. Rao, C. S. R., Poddar, B. C., Basu, K. K. and Dutta, A. K., Precambrian stratigraphy of Rajasthan $-\mathrm{a}$ review. Rec. Geol. Surv. India, 1971, 101, 60-79.

17. Choudhary, A. K., Gopalan, K. and Sastry, C. A., Present status of the geochronology of the Precambrian rocks of Rajasthan. Tectonophysics, 1984, 105, 131-140.

18. Heron, A. M., The geology of north-eastern Rajputana and adjacent districts, Geological Survey of India, Hyderabad. Memoirs, 1917, 45, 69-72.

19. Kröner, A. et al., Palaeoproterozoic ancestry of Pan-African highgrade granitoids in southernmost India: Implications for Gondwana reconstructions. Gondwana Res., 2015, 27, 1-37.

20. Miller, J. S., Santosh, M., Pressley, R. A., Clements, A. S. and Rogers, J. J. W., A Pan-African thermal event in southern India. J. Southeast Asian Earth Sci., 1996, 14, 127-136.

21. Rajesh, H. M. and Santosh, M., Alkaline magmatism in peninsular India. In Archaean Proterozoic Terrains South. India within East Gondwana. Memoirs, Gondwana Research Group, 1996, no. 3, pp. 91-116.

22. Wiebe, R. A., Proterozoic anorthosite complexes. In Developments in Precambrian Geology, Elsevier, Socorro, New Mexico, 1992, vol. 10, pp. 215-261.

23. Kumar, A., Charan, S. N., Gopalan, K. and Macdougall, J. D., A long-lived enriched mantle source for two Proterozoic carbonatite complexes from Tamil Nadu, southern India. Geochim. Cosmochim. Acta, 1998, 62, 515-523.

24. Adams, J. B. and Goullaud, L. H., Plagioclase feldspars: visible and near infrared diffuse reflectance spectra as applied to remote sensing. In Proceedings of 9th Lunar and Planetary Science Conference, New York, 1978, pp. 1205-1207.

25. Clark, R. N., King, T. V. V., Klejwa, M., Swayze, G. A. and Vergo, N., High spectral resolution reflectance spectroscopy of minerals. J. Geophys. Res., 1990, 95, 12653-12680.

26. Hunt, G. R., Near-infrared (1.3-2.4) $\mu \mathrm{m}$ spectra of alteration minerals - potential for use in remote sensing. Geophysics, 1979, 44, 1974-1986.

27. Hunt, G. R., Visible and near-infrared spectra of minerals and rocks: III. Oxides and hydro-oxides. Mod. Geol., 1971, 2, 195205.

28. Hunt, G. R. and Salisbury, J. W., Visible and near infrared spectra of minerals and rocks. II. Carbonates. Mod. Geol., 1971, 2, 23-30.

29. Singer, R. B., Near-infrared spectral reflectance of mineral mixtures: systematic combinations of pyroxenes, olivine, and iron oxides. J. Geophys. Res. Solid Earth, 1981, 86, 7967-7982.

30. Subramaniam, A. P., Mineralogy and petrology of the Sittampundi complex, Salem district, Madras State, India. Geol. Soc. Am. Bull., 1956, 67, 317-390.

31. Ground Water Department Rajasthan, Hydrogeological Atlas of Rajasthan: Banswara District, 2013, pp. 1-23; https://phedwater. rajasthan.gov.in/content/raj/water/en/ground-water/publicationsreports/ground-water-atlas.html (accessed on 15 June 2020).

32. Deol, S., Chattopadhyay, A. and Deb, M., Deformation and metamorphism of gold-sulphide lodes in the Bhukia-Jagpura gold prospect, Rajasthan: implications for ore genesis. J. Earth Syst. Sci., 2014, 123, 1-13.

33. Shaif, M., Siddiquie, F. N. and Mukhopadhyay, S., Petrographic characteristics of manganese bearing rocks of Banswara Manganese Ores Belt, District Banswara, Rajasthan (India). Open J. Geol., 2017, 07, 1047-1062.

34. Department of Geology and Mining, Government of Tamil Nadu, District Survey Report for calcite, Salem district, 2019; https://salem.nic.in/salem-district-mineral-survey-report-new/

35. Anbazhagan, S., Sainaba, N. K. and Arivazhagan, S., Remote sensing study of Sittampundi anorthosite complex, India. J. Indian Soc. Remote Sensing, 2012, 40, 145-153.
36. Arivazhagan, S. and Anbazhagan, S., ASTER data analyses for lithological discrimination of Sittampundi Anorthositic Complex, Southern India. Geosci. Res., 2017, 2, 196-209.

37. Karmakar, S., Mukherjee, S., Sanyal, S. and Sengupta, P., Origin of peraluminous minerals (corundum, spinel and sapphirine) in a highly calcic anorthosite from the Sittampundi Layered Complex, Tamil Nadu, India. Contrib. Mineral. Petrol., 2017, 172, 67.

38. Heiken, G. H., Vaniman, D. T. and French, B. M., Lunar Sourcebook, Cambridge University Press, New York, USA, 1991; https://www.lpi.usra.edu/publications/books/lunar_sourcebook/

39. Anbazhagan, S. and Arivazhagan, S., Reflectance spectra of analog anorthosites: implications for lunar highland mapping. Planet. Space Sci., 2010, 58, 752-760.

40. Hunt, G. R. and Evarts, R. C., The use of near-infrared spectroscopy to determine the degree of serpentinization of ultramafic rocks. Geophysics, 1981, 46, 316-321.

41. Ducart, D. F., Silva, A. M., Labouré, C., Toledo, B. and Assis, L. M. De, Mapping iron oxides with Landsat-8/OLI and EO-1/Hyperion imagery from the Serra Norte iron deposits in the Carajás Mineral Province, Brazil. Brazilian J. Geol., 2016, 46, 331-349.

42. Kopăcková, V. and Koucká, L., Integration of absorption feature information from visible to longwave infrared spectral ranges for mineral mapping. Remote Sensing, 2017, 9, 8-13.

43. Ahmad, A., Kallukalam, T. J. and Nair, A. M., A comparative study of charnockite rocks based on spectroscopic and mineralogical analysis. In Lunar and Planetary Science Conference, Texas, USA, 2020.

44. Yamamoto, S. et al., Massive layer of pure anorthosite on the Moon. Geophys. Res. Lett., 2012, 39(13), 11-12.

45. Howie, R. A., The geochemistry of the charnockite series of Madras, India. Earth Environ. Sci. Trans. R. Soc. Edinburgh, 1955, 62, 725-768.

46. Adams, J. B., Visible and near-infrared diffuse reflectance spectra of pyroxenes as applied to remote sensing of solid objects in the solar system. J. Geophys. Res., 1974, 79, 4829-4836.

47. Clark, R. N., Spectroscopy of rocks and minerals, and principles of spectroscopy. Man. Remote Sensing, 1999, 3, 3-58.

48. Press, W. H. and Teukolsky, S. A., Savitzky-Golay smoothing filters. Comput. Phys., 1990, 4, 669.

49. Tsai, F.-A. and Philpot, W. D., Derivative analysis of hyperspectral data for detecting spectral features. In IGARSS'97. IEEE International Geoscience and Remote Sensing Symposium Proceedings. Remote Sensing - A Scientific Vision for Sustainable Development, Singapore, 3-8 August 1997, vol. 3, 12431245 .

50. Wu, J., Liu, Y., Wang, J. and He, T., Application of Hyperion data to land degradation mapping in the Hengshan region of China. Int. J. Remote Sensing, 2010, 31, 5145-5161.

51. Sharma, A. and Rajamani, V., Weathering of charnockites and sediment production in the catchment area of the Cauvery River, southern India. Sediment. Geol., 2001, 143, 169-184.

52. Kokaly, R. F. et al., USGS Spectral Library Version 7 US Geological Survey Data Service, Reston, VA, 1035, 2017, p. 68.

53. Kruse, F. A. et al., Comparison of AVIRIS and Hyperion for hyperspectral mineral mapping. In 11th JPL Airborne Geoscience Workshop, California, USA, 2002.

54. Middleton, E. M. et al., EO-1/Hyperion: Nearing Fourteen Years of Successful Mission Science Operation and End of Mission Plans. In Proceedings of IGARSS (IEEE Geoscience and Remote Sensing Society), Québec, Canada, 2014, pp. 4-7.

55. Tou, J. T. and Gonzalez, R. C., Pattern Recognition Principles, Addison-Wesley Publ. Company, Reading, Massachusetts, USA, 1974.

56. Jensen, J. R. et al., Introductory Digital Image Processing: A Remote Sensing Perspective, Prentice-Hall Inc, New Jersey, USA, 1996, vol. 2, pp. 1-318. 
57. Pearlman, J. S., Barry, P. S., Segal, C. C., Shepanski, J., Beiso, D. and Carman, S. L., Hyperion, a space-based imaging spectrometer. IEEE Trans. Geosci. Remote Sensing, 2003, 41, 1160-1173.

58. Van Mol, B. and Ruddick, K., The Compact High Resolution Imaging Spectrometer (CHRIS): the future of hyperspectral satellite sensors. Imagery of Oostende coastal and inland waters. In Proceedings of the Airborne Imaging Spectroscopy Workshop Bruges, Belgium, 2004, pp. 1-10.

59. Bhattacharya, B. K. et al., An overview of AVIRIS-NG airborne hyperspectral science campaign over India. Curr. Sci., 2019, 116, 1082-1088.

60. Kiran Kumar, A. S. and Chowdhury, A. R., Hyper-spectral imager in visible and near-infrared band for lunar compositional mapping. J. Earth Syst. Sci., 2005, 114, 721-724.

61. Gupta, R. P., Remote Sensing Geology, Springer, Heidelberg, 2013, vol. 2, pp. 1-428.

62. Mitra, S., Fundamentals of Optical, Spectroscopic, and X-ray Mineralogy, New Age International, New Delhi, 1996, pp. 1-336.

63. Deng, Y., Wu, C., Li, M. and Chen, R., RNDSI: a ratio normalized difference soil index for remote sensing of urban/suburban environments. Int. J. Appl. Earth Obs. Geoinf., 2015, 39, 40-48.

64. Qi, J., Chehbouni, A., Huete, A. R., Kerr, Y. H. and Sorooshian, S., A modified soil adjusted vegetation index. Remote Sensing Environ., 1994, 48, 119-126.
65. Rowan, L. C. and Mars, J. C., Lithologic mapping in the Mountain Pass, California area using advanced spaceborne thermal emission and reflection radiometer (ASTER) data. Remote Sensing Environ., 2003, 84, 350-366.

66. Kalinowski, A. and Oliver, S., ASTER Mineral Index Processing Manual, Remote Sensing Applications, Geoscience Australia, 2004, vol. 37 , p. 36

67. Hewson, R., Robson, D., Mauger, A., Cudahy, T., Thomas, M. and Jones, S., Using the Geoscience Australia-CSIRO ASTER maps and airborne geophysics to explore Australian geoscience. J. Spat. Sci., 2015, 60, 207-231.

ACKNOWLEDGEMENTS. We thank the Geological Survey of India and Survey of India for mineralogical reports and maps respectively. We also thank the Italian Space Agency for making the PRISMA datasets free to access.

Received 19 June 2020; revised accepted 26 August 2020

doi: $10.18520 / \mathrm{cs} / \mathrm{v} 119 / \mathrm{i} 8 / 1267-1281$ 